\title{
Results of Coronary Artery Bypass Grafting in Non-dialysis Patients with Renal Dysfunction
}

\author{
Onichi Furuya $^{1,2}$, Shinichi Higashiue ${ }^{1}$, Satoshi Kuroyanagi ${ }^{1}$, Masatoshi Komooka ${ }^{1}$, Saburo Kojima ${ }^{1}$, \\ Makoto Matsuura $^{1}$, Kensuke Kasuga ${ }^{1}$, Tetsushi Takemoto ${ }^{1}$, and Norihiko Hiramatsu ${ }^{1}$
}

\begin{abstract}
Aim: We investigated the Results of coronary artery bypass grafting (CABG) performed on non-dialysis patients with renal dysfunction at our hospital. Methods: Fourteen hundred and eighty-two patients who underwent isolated CABG between January 2007 and December 2018 were classified into 3 groups: C-group (544 nondialysis patients with stage 3a-5 chronic kidney disease [CKD]); N-group (785 patients with stage 1-2 CKD identified as those with normal renal function); and $\mathrm{H}$-group (153 hemodialysis patients). A propensity score matching was performed, we compared 1050 cases of the matched 525 cases between the C-group and the $\mathrm{N}$-group, and 264 cases of 132 cases between C- group and H-group, respectively. Results: In surgical mortality, no significant difference was observed between the $\mathrm{C}$-group and the $\mathrm{N}$-group/the $\mathrm{H}$-group and even after matching. In hospital mortality rate, the C-group was significantly higher than the $\mathrm{N}$-group $(\mathrm{p}=0.002)$, but there was no significant difference between the C-group and the H-group $(p=0.122)$. After the matching, inhospital mortality was significantly higher than in $\mathrm{N}$-group $(\mathrm{p}=0.014)$ and significantly lower than in $\mathrm{H}$-group $(p=0.019)$. In long-term postoperative results, the $\mathrm{C}$-group was worse than the $\mathrm{N}$-group, but better than the $\mathrm{H}$-group and even after matching. The survival rates in descending order by CKD stage were $\mathrm{N}$-group, stage $3 a$, stage $3 b$, and stage 4/stage 5/H-group, with a significant difference. The long-term postoperative survival rates in stage 4, stage 5, and $\mathrm{H}$-group were all equivalent. Conclusion: There was no significant difference in surgical mortality from $\mathrm{C}$-group compared with $\mathrm{N}$-group or $\mathrm{H}$-group. In long-term postoperative outcomes, the C-group was worse than the $\mathrm{N}$-group, but better than the H-group. However, the long term result of CKD stage 4 and 5 may have poor results comparable to those in the dialysis patients.
\end{abstract}

KEY WORDS: CABG, CKD, dialysis

\section{Introduction}

Preoperative renal dysfunction is a major risk factor in heart surgery ${ }^{1-4)}$. On the one hand, it is common knowledge that results of heart surgery in dialysis patients, in particular, are extremely poor, but on the other hand, there are only a few reports that focused on non-dialysis patients with chronic kidney disease (CKD) in Japan ${ }^{5,6}$. We report the outcomes of coronary artery bypass grafting (CABG) performed on non-dialysis patients with renal dysfunction at our hospital.

${ }^{1}$ Kishiwada Tokusyukai Hospital, 4-chome-27-1 Kmoricho, Kishiwada, Osaka, 506-0042 Japan, ${ }^{2}$ Shiga University of Medical Science, Division of Cardiovascular Surgery

This paper was presented at the 31st Annual Meeting of the Japanese Coronary Association 2017 in Osaka.

E-mail: of2849@gmail.com

Received: January 28, 2020; Accepted: June 19, 2020

doi: 10.7793/jcad.26.20-00003

\section{Materials and methods}

\section{Patient background}

We conducted a study on 1482 patients who underwent isolated CABG at our medical center between January 2007 and December 2018. Patients who underwent redo CABG or minimally invasive direct coronary artery bypass grafting (MIDCAB) and patients with unknown preoperative creatinine levels were excluded. Estimated glomerular filtration rate (eGFR) was advocated by Clinical Practice Guidelines for CKD 2018 published by Japanese Society of Nephrology, developed on the basis of the Kidney Disease Improving Global Outcomes guidelines. The eGFR (in unit of $\mathrm{ml} / \mathrm{min} / 1.73 \mathrm{~m}^{2}$ ) in all patients (except those on dialysis) was calculated using the following formulae: $194 \times$ serum creatinine $(\mathrm{mg} / \mathrm{dl})^{-1.094} \times$ age $(\text { years })^{-0.287}(\times 0.739$ if female $)$, and renal dysfunction was defined as eGFR $<60 \mathrm{ml} / \mathrm{min} / 1.73 \mathrm{~m}^{2}$. The C-group (544 non-dialysis patients with stage 3a-5 CKD) was compared to the N-group (785 patients with stage 1-2 CKD identified as those with normal renal function) and the H-group (153 hemodialysis patients). A propensity score matching was 
performed to identify appropriate matched-pair of patients between each group. We compared 1050 cases of the matched 525 cases between the C-group and the N-group, and 264 cases of 132 cases between $\mathrm{C}$ - group and $\mathrm{H}$-group, respectively.

\section{Surgical technique}

Median sternotomy was used to perform operations on all patients. As a basic strategy, the left internal thoracic artery (LITA) was skeletonized and harvested by using an electrosurgical knife or an ultrasonic harmonic scalpel and then used as an in situ graft anastomosed to the left anterior descending coronary artery. Using the endoscopic technique to harvest saphenous vein graft (SVG) from the thigh was considered as a basic strategy, but when the characteristics and diameter of harvested SVG were not suitable for bypass grafting, open harvesting of the saphenous vein from the leg was used as a graft. Partial clamping of the ascending aorta was used for the proximal anastomosis of SVG as a basic strategy, but when partial aortic clamping was difficult due to atheromatous changes or calcification identified through palpation or epiaortic echo, proximal anastomosis was performed with the PAS-Port system (Cardica Inc, Rewood City, USA). A cardiopulmonary bypass conventional CABG or onpump beating $\mathrm{CABG}$ was attached to a venous cannula in the right atrium and an aortic cannula in the ascending aorta. The cross-clamp technique was used in conventional CABG, and cardioplegic solution was infused antegradely via the ascending aorta. In terms of on-pump beating CABG or off-pump CABG (OPCAB), coronary blood flow was peripherally maintained by a shunt inserted into the incised coronary artery.

\section{End points}

The end points were overall death, cardiac death, and major adverse cardiac or cerebrovascular events (MACCE). Cardiac death included deaths caused by myocardial infarction, heart failure, or sudden death. MACCE was defined as overall death, myocardial infarction, arrhythmia requiring revascularization and inpatient treatment, and cerebral infarction and hemorrhage.

\section{Statistical analysis}

This is a single-center, retrospective, observational study. We compared the patient characteristics, operative data, and early results by Chi square test or Fisher's exact test for categorical variables, the student' $t$-test or Mann-Whitney U test for continuous variables. A propensity score was created using a regression model based on the following 17 patients characteristics: age, sex, diabetes mellitus, hypertension, dyslipidemia, smoking, chronic obstructive pulmonary disease (COPD), left ventricular ejaction fraction (LVEF), triple vessel disease, left main trunk disease, history of cerebrovascular disease, carotid stenosis, atherosclerosis obliterans (ASO), history of percutaneous coronary intervention, acute myocardial infarction, urgency and intra-aortic balloon pump (IABP) requirement. We performed a one-to- one matched analysis by nearest neighbor within caliper $( \pm 0.20)$ without replacement on the basis of the estimated score of each patients. Logistic regression was used to analyze the risk of mortality within 30 days after surgery. The Kaplan-Meier method was used to calculate a long-term postoperative survival rate, an avoidable mortality rate from heart disease, and an avoidable MACCE rate. And the comparison by log-rank test was performed between each group. The long-term postoperative risks of mortality and MACCE were analyzed using the Cox proportional-hazards model. A p-value $<0.05$ in each analysis indicated a statistically significant difference. A statistical analysis software, SPSS for Windows version 11.5.1 (SPSS. Inc., Chicago, IL., USA), was used for data analysis.

\section{Ethics}

This study was conducted in accordance with the Declaration of Helsinki.

\section{Results}

\section{Patient characteristics}

The mean age of all patients was $68.9 \pm 9.5$ years, and $78.3 \%$ of total were male patients $(n=1160 / 1482)$. The mean follow-up periods (months) for all patients, $\mathrm{C}$-group, $\mathrm{N}$-group, and $\mathrm{H}$-group were $48.8 \pm 41.4,45.5 \pm 40.9,54.3 \pm 42.7$, and $31.8 \pm 28.5$, respectively.

When compared to the $\mathrm{N}$-group, the C-group had a higher mean age. In the following patient backgrounds, the C-group had higher percentages than the N-group: females, $\geq 80$ years of age, diabetes, low left ventricular function $(\mathrm{LVEF}<35 \%)$, ASO, carotid stenosis, and past history of cerebrovascular event. The mean preoperative LVEF in the C-group was lower than that in the $\mathrm{N}$-group. After matching, the C-group had a higher mean age and had higher percentages than the $\mathrm{N}$-group: $\geq 80$ years of age, low left ventricular function, and carotid stenosis. The mean preoperative LVEF in the C-group was lower than that in the $\mathrm{N}$-group.

In comparison with the $\mathrm{H}$-group, the C-group had a higher mean age. In the following patient backgrounds, the C-group had also higher percentages than the H-group: $\geq 80$ years of age, triple vessel disease, past history of acute myocardial infarction, dyslipidemia, and preoperative IABP. In the mean preoperative LVEF, the C-group was higher than the H-group, but in the percentages of patients with diabetes and ASO, the C-group was lower than the H-group. After matching, the C-group had higher percentages of patients with past history of acute myocardial infarction than the H-group. In the mean preoperative LVEF, the C-group was higher than the H-group, but in the percentages of patients with triple vessel diseases, the $\mathrm{C}$-group was lower than the H-group (Table 1). 


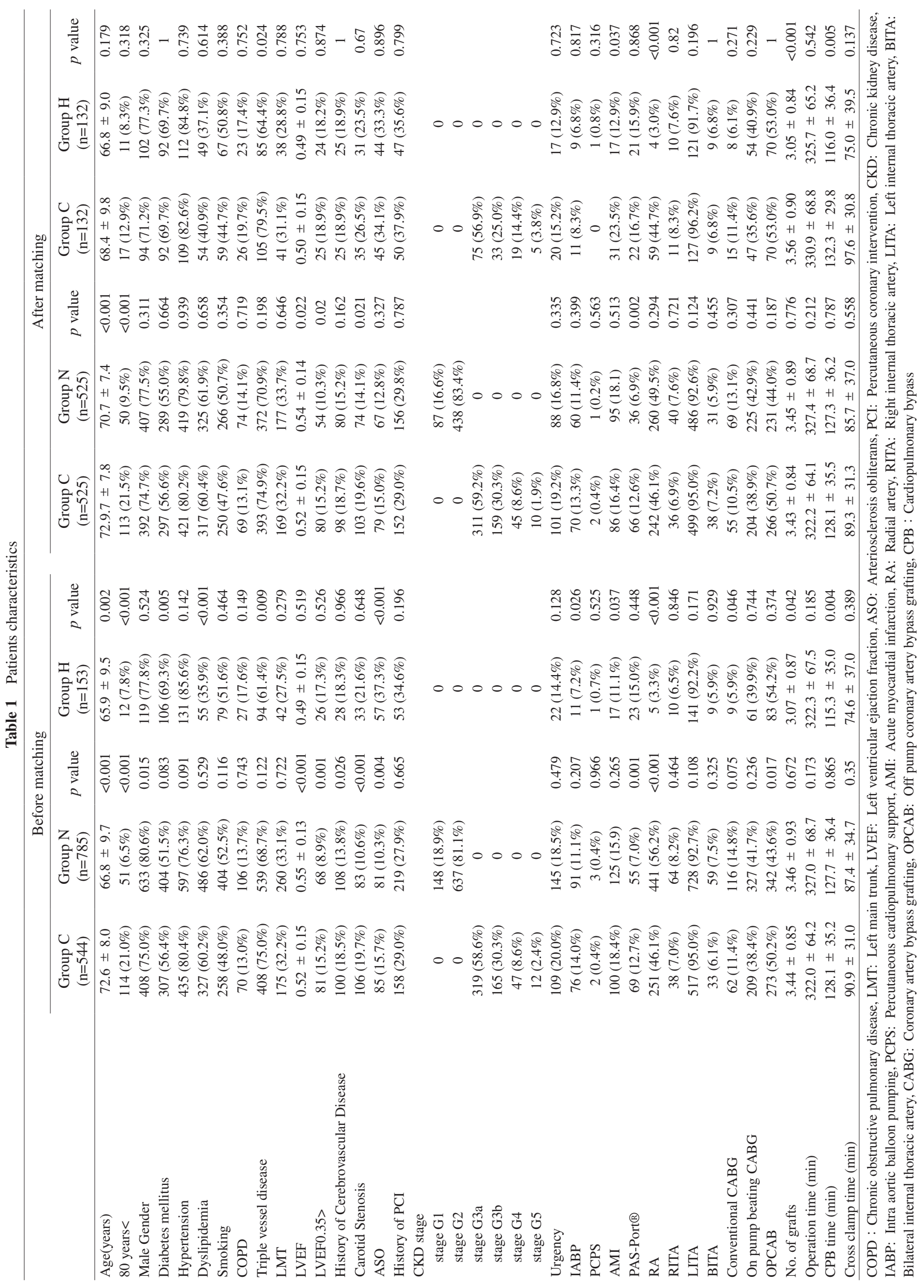


Table 2 Early result

\begin{tabular}{|c|c|c|c|c|c|c|c|c|c|c|c|}
\hline & \multicolumn{5}{|c|}{ Before matching } & \multicolumn{6}{|c|}{ After matching } \\
\hline & $\begin{array}{l}\text { Group C } \\
(\mathrm{n}=544)\end{array}$ & $\begin{array}{l}\text { Group N } \\
(\mathrm{n}=785)\end{array}$ & $p$ value & $\begin{array}{c}\text { Group H } \\
(\mathrm{n}=153)\end{array}$ & $p$ value & $\begin{array}{l}\text { Group C } \\
(\mathrm{n}=525)\end{array}$ & $\begin{array}{l}\text { Group N } \\
(\mathrm{n}=525)\end{array}$ & $p$ value & $\begin{array}{l}\text { Group C } \\
(\mathrm{n}=132)\end{array}$ & $\begin{array}{c}\text { Group H } \\
(\mathrm{n}=132)\end{array}$ & $p$ value \\
\hline Operative death (30days) & $8(1.5 \%)$ & $4(0.5 \%)$ & 0.081 & $6(3.9 \%)$ & 0.094 & $7(1.3 \%)$ & $3(0.6 \%)$ & 0.341 & $1(0.8 \%)$ & $6(4.5 \%)$ & 0.12 \\
\hline In hospital death & $21(3.9 \%)$ & $9(1.1 \%)$ & 0.002 & $11(7.2 \%)$ & 0.122 & $19(3.6 \%)$ & $6(1.1 \%)$ & 0.014 & $2(1.5 \%)$ & $11(8.2 \%)$ & 0.019 \\
\hline Perioperative myocardial infarction & 0 & $1(0.1 \%)$ & 0.853 & $0(0 \%)$ & 1 & 0 & 0 & 1 & 0 & 0 & 1 \\
\hline Central neurological event & $1(0.5 \%)$ & $1(0.1 \%)$ & 0.646 & $0(0 \%)$ & 0.853 & $1(0.2 \%)$ & 0 & 0.873 & 0 & 0 & 1 \\
\hline Initiation of dialysis & $2(0.9 \%)$ & 0 & 0.326 & - & - & $2(0.4 \%)$ & 0 & 0.794 & 0 & - & - \\
\hline
\end{tabular}

\section{Surgical data}

There was no significant difference in operating time between each group. In pump time (indicating how long patients were on a cardiopulmonary bypass) and cross-clamp time, there was no significant difference between the $\mathrm{C}$-group and the $\mathrm{N}$-group, but the C-group showed a significantly higher pump time than the $\mathrm{H}$-group. These were similar results after matching.

In surgical procedures, there was no significant difference in the percentage of patients in the C-group who underwent conventional $\mathrm{CABG}$ and on-pump beating $\mathrm{CABG}$, but the percentage of those who underwent off-pump coronary artery bypass grafting $(\mathrm{OPCAB})$ was higher compared to that in the $\mathrm{N}$-group. There was no significant difference in the percentage of patients in the C-group who underwent on-pump beating CABG and OP$\mathrm{CAB}$, but the percentage of those who underwent conventional CABG was higher compared to that in the N-group. After matching, there was no significant difference in surgical procedure between C-group and $\mathrm{N}$-group or H-group.

In the mean number of peripheral anastomosis sites, no significant difference was observed between the C-group and the $\mathrm{N}$-group, but when compared to the H-group, the C-group showed a significantly larger number than the H-group. These were similar results after matching.

In the graft design, there was no significant difference in the percentages of LITA and bilateral internal thoracic artery (BITA) uses between each group. The percentage of radial artery (RA) use in the C-group was significantly lower than that in the $\mathrm{N}$-group, but no significant difference was observed between the $\mathrm{C}$-group and the H-group. The percentage of PAS-Port (Cardica Inc, Rewood City, USA) use in the C-group was significantly higher than that in the $\mathrm{N}$-group, but no significant difference was observed between the $\mathrm{C}$-group and the H-group. After matching, there was no significant difference in the use of RA between the $\mathrm{C}$-group and the N-group. Other graft designs except RA result were the same as before matching (Table 1).

\section{Early postoperative outcomes}

The mortality rate within 30 days after surgery and the in hospital mortality rate were $1.2 \%(n=18)$ and $2.8 \%(n=41)$ of all patients, respectively. Other results of all patients were as follows:
Table 3 Operative death risk

\begin{tabular}{ccc}
\hline & Odds ratio (95\% Confidence Interval) & $p$ value \\
\hline Age & $1.160(1.001-1.345)$ & 0.048 \\
eGFR & $0.923(0.853-1.000)$ & 0.05 \\
AMI & $8.018(0.668-96.256)$ & 0.101 \\
History of PCI & $4.476(0.640-31.328)$ & 0.131 \\
Emergent & $3.854(0.139-107.044)$ & 0.426 \\
Smoking & $0.393(0.031-4.939)$ & 0.469 \\
LVEF & $0.976(0.885-1.076)$ & 0.628 \\
IABP & $0.673(0.060-7.535)$ & 0.748 \\
\hline
\end{tabular}

eGFR: estimated glomerular filtration rate, AMI: Acute myocardial infarction, PCI: Percutaneous coronary intervention, LVEF: Left ventricular ejaction fraction, IABP: Intra aortic balloon pumping

perioperative myocardial infarction $(n=1)$, perioperative brain stroke $(n=2)$, and initiation of dialysis $(n=2)$.

The results of the C-group were as follows: surgical 30 day mortality $(1.5 \%, \mathrm{n}=8)$, in hospital mortality $(3.9 \%, \mathrm{n}=21)$, perioperative myocardial infarction $(n=0)$, perioperative brain stroke $(n=1)$, and initiation of dialysis $(n=2)$. In surgical mortality, no significant difference was observed between the C-group and the $\mathrm{N}$-group/the $\mathrm{H}$-group. In hospital mortality rate, the C-group was significantly higher than the $\mathrm{N}$-group $(\mathrm{p}=0.002)$, but there was no significant difference between the C-group and the H-group ( $\mathrm{p}=0.122$ ). After the matching, the surgical mortality rate of the C-group was not significantly different from that of the $\mathrm{N}$-group and that of the $\mathrm{H}$-group as before the matching. In-hospital mortality was significantly higher than in N-group $(\mathrm{p}=0.014)$ and significantly lower than in H-group $(\mathrm{p}=0.019)$ (Table 2).

According to logistic regression analysis, the 30-day mortality risks were eGFR and age (Table 3 ).

\section{Long-term postoperative outcomes}

In all patients, overall 1-year, 5-year, and 10-year survival rates were $93.6 \%, 83.4 \%$, and $74.1 \%$, respectively. One-year, 5-year, and 10-year avoidable mortality rates from heart disease were $97.9 \%, 96.1 \%$, and $93.7 \%$, respectively, and 1-year, 5-year, and 10-year avoidable MACCE rates were $90.8 \% .75 .6 \%$, and 
$60.0 \%$, respectively.

When compared to each of two groups, the C-group in the survival rate was significantly lower than the N-group $(\mathrm{p}<0.001)$, but significantly higher than the H-group $(\mathrm{p}<0.001)$. In the freedom from cardiac death rate, the C-group was significantly lower than the N-group ( $\mathrm{p}=0.011)$, but there was no significant difference between the $\mathrm{C}$-group and the $\mathrm{H}$-group $(\mathrm{p}=0.260)$. In the freedom from MACCE rate, the C-group was significantly lower than the $\mathrm{N}$-group $(\mathrm{p}<0.001)$, but significantly higher than the H-group ( $<<0.001)$ (Fig. 1). The results after matching are shown below. The C-group in the survival rate was significantly lower than the $\mathrm{N}$-group $(\mathrm{p}<0.001)$, but significantly higher than the $\mathrm{H}$-group $(\mathrm{p}<0.001)$ as before matching. In the freedom from cardiac death rate, the C-group was not significantly different from that of the $\mathrm{N}$-group $(\mathrm{p}=0.058)$ and that of the H-group $(\mathrm{p}=0.189)$. In the freedom from MACCE rate, the $\mathrm{C}$-group was significantly lower than the $\mathrm{N}$-group $(\mathrm{p}<0.001)$, but significantly higher than the H-group ( $p<0.001)$ as before matching (Figs. 2 and 3).

The comparison between the CKD groups is shown below. In the survival rate, the $\mathrm{N}$-group had a significantly higher than those with other stages and the H-group (Stage 3a: $\mathrm{p}=0.029$, Stage 3b: $p<0.001$, Stage 4: $p<0.001$, Stage 5: $p<0.001$, H-group: $\mathrm{p}<0.001)$. Patients with stage $3 \mathrm{a}$ had a significantly higher than those with stage $3 b, 4$, and 5 and the H-group (Stage 3b: $p=0.001$, Stage 4: $p<0.001$, Stage 5: $p=0.005$, H-group: $\mathrm{p}<0.001)$. Patients with stage $3 \mathrm{~b}$ had a significantly higher than those with stage 4 and H-group (Stage 4: $<<0.001$, Stage 5: $\mathrm{p}=0.251$, H-group: $\mathrm{p}=0.001$ ). There was no significant difference between Stage 4, Stage 5 and H-group (Fig. 4). In the freedom from cardiac death, when compared to each stage of CKD, the $\mathrm{N}$-group had a significantly higher avoidable mortality rate from cardiac event than those with stage $3 b, 4$ and the H-group (Stage 3a: $p=0.455$, Stage 3b: $p=0.001$, Stage 4: $p=0.015$, Stage 5: $\mathrm{p}=0.136$, H-group: $\mathrm{p}=0.003$ ). Patients with stage $3 \mathrm{a}$ were a significantly higher rates than those with stage $3 \mathrm{~b}$ and 4 and the H-group (Stage 3b: $\mathrm{p}=0.031$, Stage 4: $\mathrm{p}=0.036$, Stage 5: $p=0.235$, H-group: $p=0.037$ ). About, patients with stage $3 b$, there was no significant difference between patients with stage 4 and 5 and the H-group (Stage 4: $\mathrm{p}=0738$, Stage 5: $\mathrm{p}=0.821$, H-group: $\mathrm{p}=0.968$ ). About patients with stage 4, there was no significant difference between patients with stage $3 \mathrm{a}$ and 5 and the H-group (Stage 5: $\mathrm{p}=0.942$, H-group: $\mathrm{p}=0.673$ ). In the patients with stage 5 , there was no significant difference in the rate between other groups (Fig. 4). In the freedom from MACCE, the $\mathrm{N}$-group had a significantly higher rate than those with stage $3 \mathrm{~b}$, 4 and 5 and the H-group (Stage 3a: p=0.069, Stage 3b: $p<0.001$, Stage 4: $\mathrm{p}<0.001$, Stage 5: $\mathrm{p}=0.024$, H-group: $\mathrm{p}<0.001)$. Patients with stage $3 \mathrm{a}$ were a significantly higher rate than those with stage $3 b$, and 4 and the H-group (Stage $3 b$ : $p=0.004$, Stage
4: $\mathrm{p}<0.001$, Stage 5: $\mathrm{p}=0.080$, H-group: $\mathrm{p}<0.001)$. Patients with stage $3 \mathrm{~b}$ had a significantly higher rate than those with stage 4 and the H-group (Stage 4: $\mathrm{p}=0.010$, Stage 5: $\mathrm{p}=0.561$, H-group: $p<0.001)$. There was no significant difference between Stage 4, Stage 5 and H-group (Fig. 4).

In the C-group, a multivariate analysis showed the following factors: COPD, eGFR, ASO, age and preoperative LVEF (Table 4). The same analysis revealed that the long-term postoperative risks of MACCE were carotid artery stenosis, COPD, eGFR, ASO, age and preoperative LVEF (Table 5).

\section{Discussion}

The outcomes of non-dialysis patients with renal dysfunction who underwent $\mathrm{CABG}$ (C-group) at our medical center were compared to those of patients with normal renal function (N-group) and dialysis patients (H-group). As a result, there was no significant difference in surgical mortality between each group, but in hospital mortality, the C-group was worse than the $\mathrm{N}$-group, but better than the H-group. In long-term postoperative outcomes, the C-group was worse than the N-group, but better than the H-group. The survival rates in descending order by CKD stage were $\mathrm{N}$-group (stage 1-2), stage $3 \mathrm{a}$, stage $3 \mathrm{~b}$, and stage $4 /$ stage $5 / \mathrm{H}$-group, with a significant difference. The longterm postoperative survival rates were equivalent among stage 4 , stage 5, and H-group.

Reports on CKD severity based on $\mathrm{eGFR}^{7-13)}$ mention that eGFR is a strong predictive risk factor of $\mathrm{CABG}$, and severe CKD increases surgical mortality 3-4 times. Furthermore, these reports also state that independent predictive factors of surgical mortality are emergency case, reoperation, concurrent valve procedure, preoperative shock, and past history of brain infarction. Concerning long-term outcomes after CABG, Chonchol et al. ${ }^{13)}$ showed that CKD (eGFR $\left.<60 \mathrm{ml} / \mathrm{min} / 1.73 \mathrm{~m}^{2}\right)$ negatively affects the mean prognosis of 3.1 years (HR, 1.89). According to Lin et al., ${ }^{11)}$ the mean 4.7-year follow-up showed that eGFR is the independent risk factor of life expectancy (HR, 1.54). In Japan, Komi$\mathrm{ya}^{5)}$ examined long-term follow-up results of 659 patients (divided into 5 categories: 4 groups of eGFR [normal, $\geq 90$; mild, 60 89 ; moderate, 30-59 ; and severe, $<30 \mathrm{ml} / \mathrm{min} / 1.73 \mathrm{~m}^{2}$ ] and dialysis) who were planning to undergo $\mathrm{CABG}$ alone. As a result, the higher the degree of renal function deterioration, the lower the five-year survival rates of the patients. Araki et al. ${ }^{6}$ reported that the CKD group $\left(e G F R<50 \mathrm{ml} / \mathrm{min} / 1.73 \mathrm{~m}^{2}\right)$ had a significantly lower avoidable MACCE rate than the non-CKD group ; however, their report did not include a study of each CKD severity class and a report on survival rates. These reports suggest that the survival rates are falling in ascending order by CKD severity: stage $3 \mathrm{a}$, stage $3 \mathrm{~b}$, and stage 4 , because of eGFR $<60 \mathrm{ml} / \mathrm{min} / 1.73 \mathrm{~m}^{2}$, which was as we had expected. Further- 


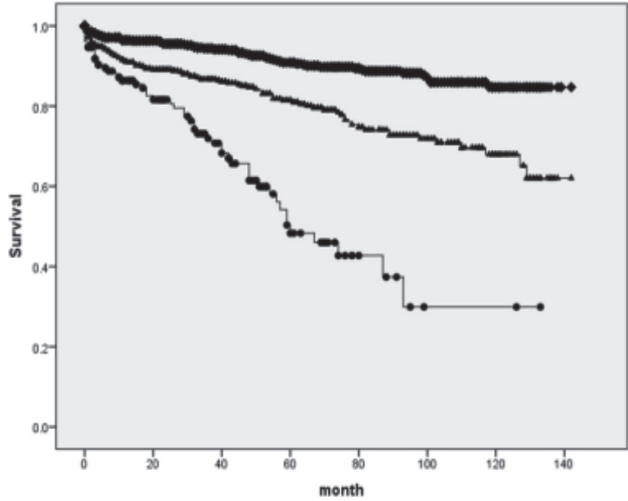

(A)

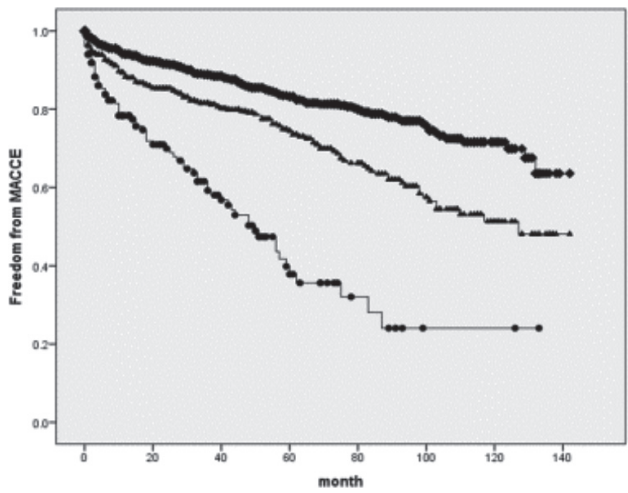

(C)

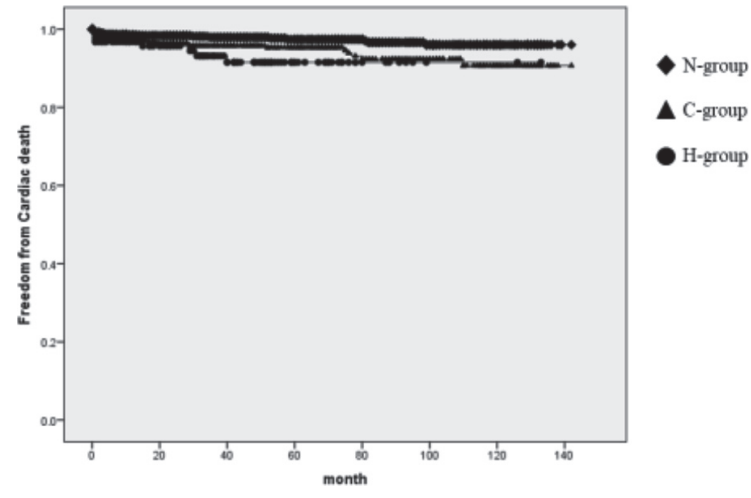

(B)

A: All case of death

B: Freedom from cardiac death

C: Freedom from MACCE

CKD: Chronic kidney disease, MACCE: Major adverse cardiac or cerebrovascular event

Fig. 1 Long-term result before the matching divided by non-CKD, non-dialysis CKD and dialysis patients.

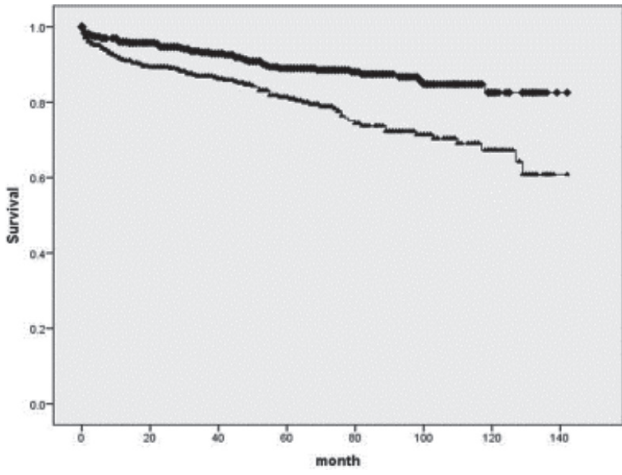

(A)

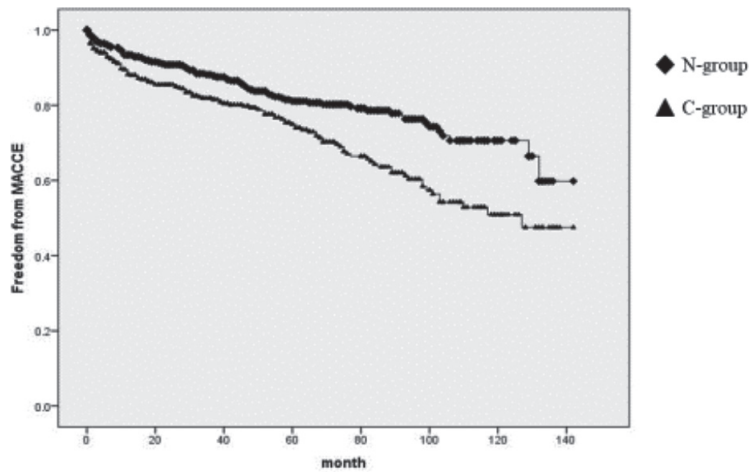

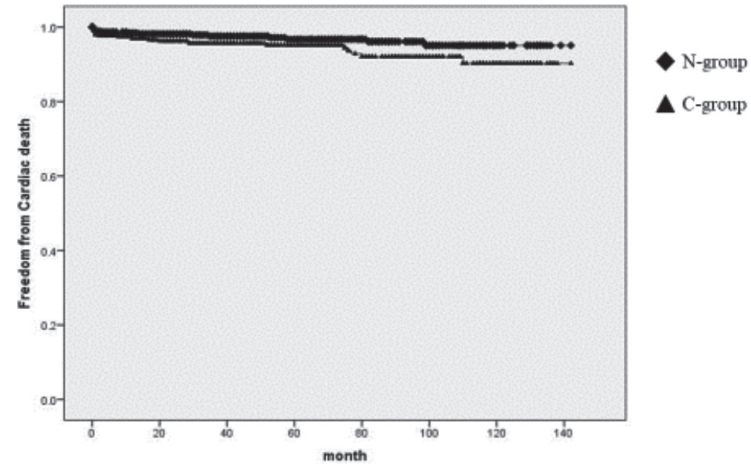

(B)

\section{A: All case of death \\ B: Freedom from cardiac death \\ C: Freedom from MACCE}

CKD: Chronic kidney disease, MACCE: Major adverse cardiac or cerebrovascular event

(C)

Fig. 2 Long-term result after the matching divided by non-CKD and non-dialysis CKD. 


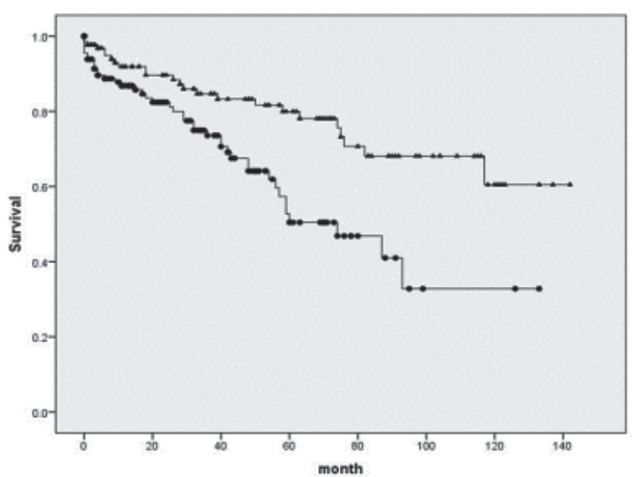

(A)

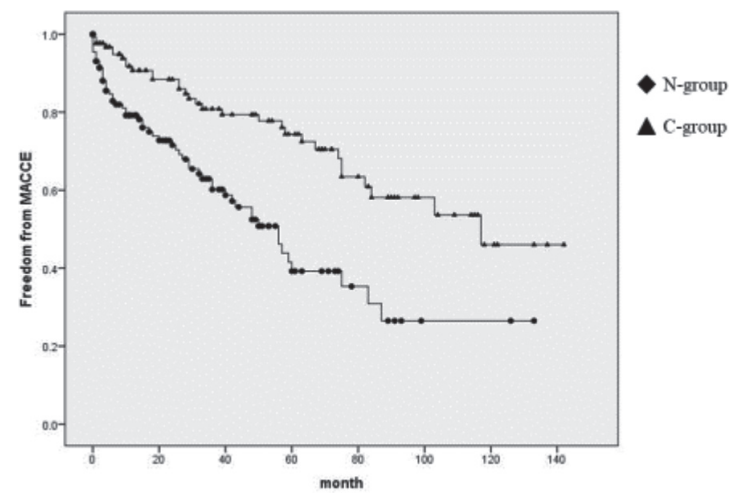

(C)

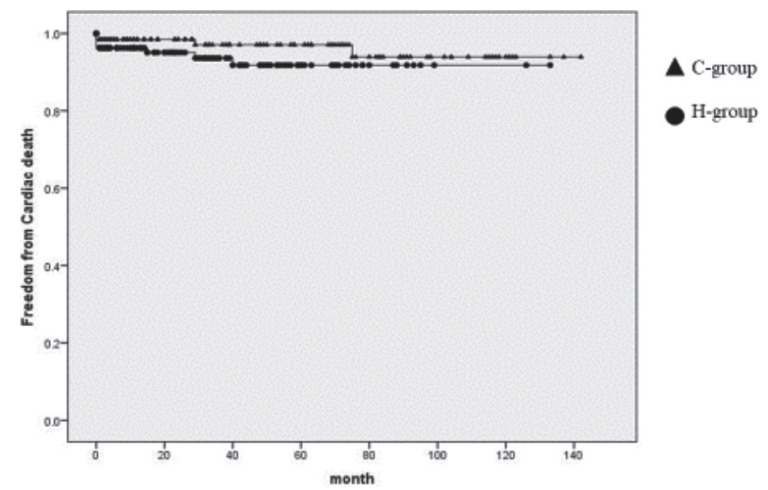

(B)

A: All case of death

B: Freedom from cardiac death

C: Freedom from MACCE

CKD: Chronic kidney disease, MACCE: Major adverse cardiac or cerebrovascular event

Fig. 3 Long-term result after the matching divided by non-dialysis CKD and dialysis patients.

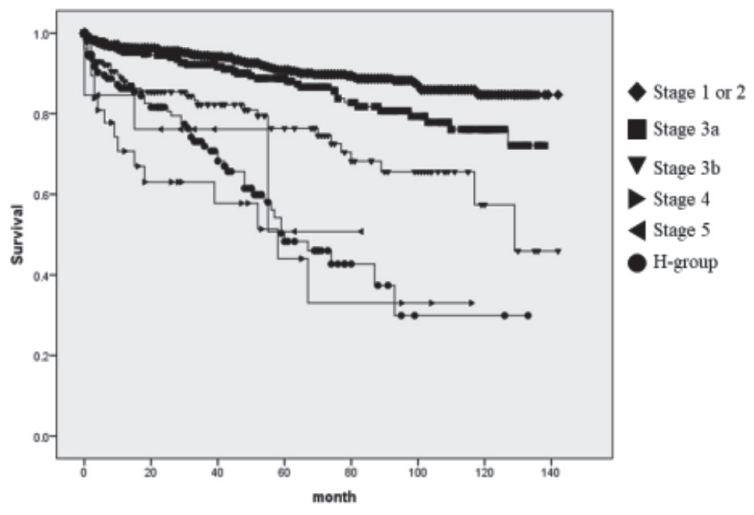

(A)

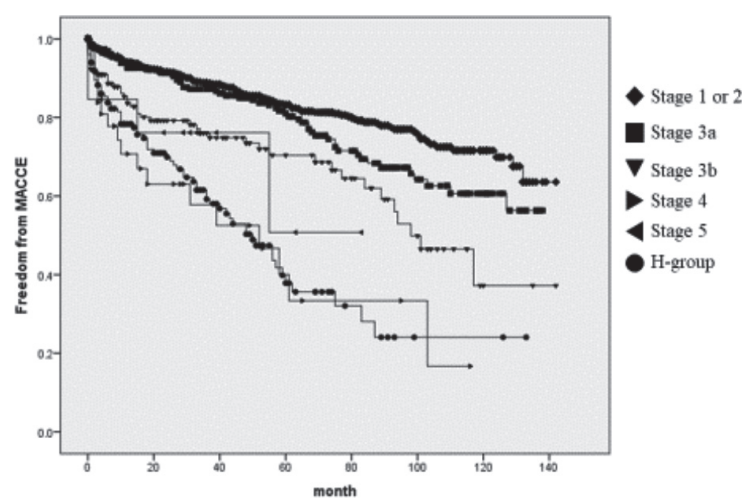

(C)

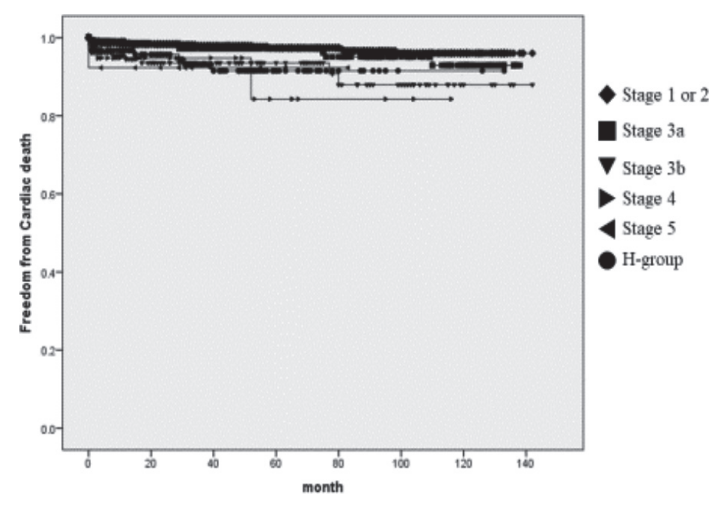

(B)
A: All case of death
B: Freedom from cardiac death
C: Freedom from MACCE

CKD: Chronic kidney disease, MACCE: Major adverse cardiac or cerebrovascular event

Fig. 4 Long-term result divided by CKD stages. 
Table 4 Mortality risk

\begin{tabular}{ccc}
\hline \multicolumn{2}{c}{ Hazard ratio $(95 \%$ Confidence Interval $)$} & $p$ value \\
\hline Age & $1.095(1.059-1.132)$ & $<0.001$ \\
LVEF & $0.962(0.947-0.977)$ & $<0.001$ \\
eGFR & $0.959(0.942-0.975)$ & $<0.001$ \\
ASO & $2.439(1.439-4.128)$ & 0.001 \\
COPD & $1.989(1.071-3.694)$ & 0.029 \\
Carotid Stenosis & $1.340(0.799-2.248)$ & 0.267 \\
IABP & $1.368(0.615-3.043)$ & 0.442 \\
AMI & $0.939(0.505-1.746)$ & 0.843 \\
Emergent & $1.245(0.575-2.694)$ & 0.578
\end{tabular}

LVEF: Left ventricular ejaction fraction, ASO: Arteriosclerosis obliterans, COPD : Chronic obstructive pulmonary disease, IABP: Intra aortic balloon pumping, AMI: Acute myocardial infarction

more, there was no significant difference between outcomes of dialysis patients and patients with stage 4 and 5 CKD, which was notable because this result has not yet been reported. However, in this comparison between CKD groups, propensity score matching was not performed. Furthermore, the number of Stage 5 cases is 13 , which is not enough for statistical difference analysis. For these reasons, it is not easy to conclude that the results of Stage 4 and 5 in this study are equivalent to those in dialysis patients. Nevertheless, it may be suggested that CKD Stage 4 and Stage 5 require the same risk management as dialysis patients. Therefore, Table 6 shows the causes of death after discharge of patients with Stage $3 b$ to 5 and dialysis patients. Infection was the most common cause of death in patients with non-dialysis patients with renal dysfunction. Gangrene of limb was the most prominent cause of death in dialysis patients, but the number of deaths due to infection was not small. Risk management for infectious diseases, especially pneumonia, should be shared by non-dialysis patients and dialysis patients. And special attention should be paid to the management of ASO and diabetes mellitus in dialysis patients.

In the meantime, Charytan et al. ${ }^{12)}$ report that in case of patients with stage 3-5 CKD who were discharged from hospital after surgery, the mean 2.34-year survival rate of these patients is almost the same as that of non-CKD patients. Additionally, in order to improve prognosis of CKD patients, Kinoshita et al. ${ }^{14)}$ the research group of our medical center, conducted a study of OPCAB performed on $99.1 \%$ of 656 patients who underwent isolated CABG. As a result, the BITA group (5-year survival rate, $88 \%$ ) had a higher life expectancy than the single internal thoracic artery group (5-year survival rate, 75\%), indicating that OPCAB using BITA is effective. In terms of OPCAB and onpump CABG (ONCAB) performed on CKD patients, Wang et al. ${ }^{15)}$ reported that in meta-analysis, the OPCAB group had a significantly lower mortality rate than the ONCAB group (OR,
Table 5 MACCE risk

\begin{tabular}{ccc}
\hline \multicolumn{2}{c}{ Hazard ratio $(95 \%$ Confidence Interval $)$} & $p$ value \\
\hline Age & $1.070(1.041-1.100)$ & $<0.001$ \\
LVEF & $0.974(0.961-0.987)$ & $<0.001$ \\
eGFR & $0.970(0.956-0.984)$ & $<0.001$ \\
ASO & $1.834(1.141-2.946)$ & 0.012 \\
COPD & $1.722(1.004-2.955)$ & 0.049 \\
Carotid Stenosis & $1.564(1.016-2.409)$ & 0.042 \\
IABP & $1.228(0.580-2.601)$ & 0.592 \\
AMI & $1.140(0.678-1.916)$ & 0.622 \\
Emergent & $1.160(0.568-2.366)$ & 0.684 \\
\hline
\end{tabular}

MACCE: Major adverse cardiac or cerebrovascular event, LVEF: Left ventricular ejaction fraction, ASO: Arteriosclerosis obliterans, COPD : Chronic obstructive pulmonary disease, IABP: Intra aortic balloon pumping, AMI: Acute myocardial infarction

Table 6 The death cases after the discharge

\begin{tabular}{|c|c|c|c|c|}
\hline & $\begin{array}{c}\text { CKD } \\
\text { stage 3a } \\
(n=311)\end{array}$ & $\begin{array}{l}\text { CKD } \\
\text { stage } 3 b \\
(n=165)\end{array}$ & $\begin{array}{c}\text { CKD } \\
\text { stage } 4 \& \\
5(n=59)\end{array}$ & $\underset{(n=153)}{\mathrm{HD}}$ \\
\hline Infection & 9 & 7 & 6 & 5 \\
\hline Pneumonia & 6 & 5 & 4 & 4 \\
\hline Meningitis & & & 2 & \\
\hline Others & 3 & 2 & & 1 \\
\hline Gangrene of limb & & 2 & 1 & 13 \\
\hline Heart failure & 5 & 3 & 2 & \\
\hline Sudden death & 1 & 1 & 1 & 4 \\
\hline $\begin{array}{l}\text { Complications for reoperation } \\
\text { of cardiac surgery }\end{array}$ & & & & 3 \\
\hline Cerebrovascular disease & 4 & 2 & 1 & \\
\hline Cancer & 8 & 4 & 1 & \\
\hline Trauma & & & & 2 \\
\hline Gastrointestinal disease & 4 & & & 1 \\
\hline Hematology disease & 1 & & & \\
\hline $\begin{array}{l}\text { Renal failure (Dialysis } \\
\text { refusal) }\end{array}$ & & 1 & & \\
\hline Unknown & 1 & 1 & & \\
\hline
\end{tabular}

0.88), but in long-term postoperative mortality, there is no significant difference between two groups (OR, 1.08). On the other hand, according to Boulton et al. ${ }^{16)}$ in Emory University, outcomes in 14199 patients who underwent isolated CABG (including 8086 OPCAB patients) revealed that incidence of postoperative mortality and complications increases in proportion to 4 severity levels of preoperative renal dysfunction classified according to eGFR levels. In this regard, there was no difference in short-term postoperative outcomes between the OPCAB group and the ONCAB group. Furthermore, their long-term follow-up results showed that in the case of moderate and severe renal dysfunction (eGFR $<60 \mathrm{ml} / \mathrm{min} / 1.73 \mathrm{~m}^{2}$ ), the OPCAB group had 
worse prognosis than the ONCAB group. Univariate analysis performed in our study also showed that in both early and longterm postoperative outcomes, the use of cardiopulmonary bypass is not relevant to the risks of mortality and MACCE and is unlikely to have a negative impact on CABG. Nakayama et al. ${ }^{17)}$ reports that active use of arterial grafts, such as BITA, was effective for improving long-term prognosis of CABG patients with CKD. Regarding the use of arterial grafts, not enough data were available to compare in our study because BITA in the CKD group was less frequently used $(6.1 \%)$. Although the frequency of RA use was $46.1 \%$, our study was not appropriate to examine the effectiveness of RA use because the RA was mostly used in patients with less advanced CKD stages. The independent risk factors of long-term postoperative mortality were COPD, age, eGFR, ASO, and preoperative LVEF, which mostly increases and gets worse with age. Therefore, it seems that the thing required for risk management to improve prognosis is to avoid delay in surgical interventions. It may be possible to use BITA, but through case accumulation and verification, we should develop a strategy to improve prognosis of CKD patients who underwent CABG.

Limitations of our study include: In sufficient sample size due to a single institutional study ; A retrospective study that we did not examine $\mathrm{CABG}$ risk factors other than renal dysfunction even though our study included the cases of isolated CABG and excluded the cases of second surgery and MIDCAB; Gaps which existed among patients because a treatment plan after hospital discharge was left entirely to the physician in the hospital where patients chose after hospital discharge ; and others.

\section{Conclusion}

In isolated $\mathrm{CABG}$ at our medical center, there was no significant difference in surgical mortality from non-dialysis patients with renal dysfunction (C-group) compared with normal renal function group (N-group) or dialysis group (H-group). However, the in-hospital mortality was lower than the N-group, but better than the H-group. In long-term postoperative outcomes, the C-group was worse than the $\mathrm{N}$-group, but better than the $\mathrm{H}$-group. However, the long term result of CKD stage 4 and 5 may have poor results comparable to those in the dialysis patients.

\section{Conflicts of interest}

The authors have no conflicts of interest directly relevant to the content of this article.

\section{References}

1) O’Connor GT, Plume SK, Olmstead EM, et al: Multivariate prediction of in-hospital mortality associated with coronary artery bypass graft surgery. Northern New England Cardiovascular Disease Study Group. Circulation 1992; 85: 2110-2118

2) Anderson RJ, O'brien M, MaWhinney S, et al: Renal failure predisposes patients to adverse outcome after coronary artery bypass surgery. VA Cooperative Study \#5. Kidney Int 1999; 55: 1057-1062

3) Liu JY, Birkmeyer NJ, Sanders JH, et al: Risks of morbidity and mortality in dialysis patients undergoing coronary artery bypass surgery. Northern New England Cardiovascular Disease Study Group. Circulation 2000; 102: 2973-2977

4) Hemmelgarn BR, Southern D, Culleton BF, et al: Survival after coronary revascularization among patients with kidney disease. Circulation 2007; 110: 1890-1895

5) Komiya $\mathrm{T}$ : Coronary artery bypass surgery for patients with renal failure. J Jpn Coron Assoc 2009; 15: 246-251

6) Araki T, Itaya H, Otsuka $\mathrm{T}$ et al: Long-term clinical outcome in patients with chronic kidney disease after coronary artery bypass grafting. J Cardiol Jpn Ed 2010; 5: 13-19

7) Cooper WA, O'Brien SM, Thourani VH, et al: Impact of renal dysfunction on outcomes of coronary artery bypass surgery: results from the Society of Thoracic Surgeons National Adult Cardiac Database. Circulation 2006; 113: 1063-1070

8) Hillis GS, Croal BL, Buchan KG, et al: Renal function and outcome from coronary artery bypass grafting: impact on mortality after a 2.3year follow-up. Circulation 2006; 113: 1056-1062

9) Zakeri R, Freemantle N, Barnett V, et al: Relation between mild renal dysfunction and outcomes after coronary artery bypass grafting. Circulation 2005; 112: I-270-I-275

10) Yeo KK, Li Z, Teun JY, et al: Severity of chronic kidney disease as a risk factor for operative mortality in nonemergent patients in the California coronary artery bypass graft surgery outcomes reporting program. Am J Cardiol 2008; 101: 1269-1274

11) Lin $Y$, Zheng $Z$, Li Y, et al: Impact of renal dysfunction on long-term survival after isolated coronary artery bypass surgery. Ann Thorac Surg 2009; 87: 1079-1084

12) Charytan DM, Yang SS, McGurk S, et al: Long and short-term outcomes following coronary artery bypass grafting: in patients with and without chronic kidney disease. Nephrol Dial Transplant 2010; 25: 3654-3663

13) Chonchol MB, Aboyans V, Lacroix P, et al: Long-term outcomes after coronary artery bypass grafting: preoperative kidney function is prognostic. J Thorac Cardiovasc Surg 2007; 134: 683-689

14) Kinoshita $T$, Asai $T$, Murakami $Y$, et al: Efficacy of bilateral internal thoracic artery grafting in patients with chronic kidney disease. Ann Thorac Surg 2010; 89: 1106-1111

15) Wang Y, Zhu S, Gao P, et al: Off-pump versus on-pump coronary surgery in patients with chronic kidney disease: a meta-analysis. Clin Exp Nephrol 2018; 22: 99-109

16) Boulton BJ, Kilgo P, Guyton RA, et al: Impact of preoperative renal dysfunction in patients undergoing off-pump versus on-pump coronary artery bypass. Ann Thorac Surg 2011; 92: 595-601; discussion 602

17) Nakayama Y, Sakata R, Ura M, et al: Long-term results of coronary artery bypass grafting in patients with renal insufficiency. Ann Thorac Surg 2003; 75: 496-500 